\title{
Superconductivity of Carbon Materials — Unstable Phases
}

\author{
W. KEMPIŃSKI \\ Institute of Molecular Physics, Polish Academy of Sciences \\ Smoluchowskiego 17, 60-179 Poznań, Poland
}

\begin{abstract}
Different intercalated carbon systems: $\mathrm{K}_{x} \mathrm{C}_{60}, \mathrm{Rb}_{x} \mathrm{C}_{60}$ as well as highly oriented pyrolytic graphite + potassium with unstable structural and superconducting behavior were investigated with the EPR and magnetically modulated microwave absorption techniques. Three characteristic, well-separated EPR signals were observed for $\mathrm{A}_{x} \mathrm{C}_{60}(\mathrm{~A}=\mathrm{K}$ or $\mathrm{Rb})$ systems at the early stages of doping process. We ascribed these signals to $\mathrm{C}_{60}^{+}, \mathrm{C}_{60}^{1-}$, and $\mathrm{C}_{60}^{3-}$ radicals. Evolution of the EPR spectrum characterizes different phases of $\mathrm{K}_{x} \mathrm{C}_{60}$ system including superconducting one. Two superconducting phases with $T_{\mathrm{c}}^{(1)}=(21 \pm 0.5) \mathrm{K}$ (unstable) and $T_{\mathrm{c}}^{(2)}=(18.5 \pm 0.5) \mathrm{K}$ (final, stable) were distinctly separated for $\mathrm{K}_{x} \mathrm{C}_{60}$ system. For $\mathrm{C}_{60}$ intercalated by rubidium a similar evolution of EPR spectrum is observed. Prior to well-defined superconducting $\mathrm{Rb}_{3} \mathrm{C}_{60}$ phase was created, strong instabilities of the magnetically modulated microwave absorption signal were observed at the narrow part of the doping process. For potassium intercalated highly oriented pyrolytic graphite, EPR oscillations below $100 \mathrm{~K}$ were observed as well as Josephson hysteresis loops were registered at $5 \mathrm{~K}$.
\end{abstract}

PACS numbers: 76.30.- -, $74.70 . \mathrm{Wz}$

\section{Introduction}

The interest in carbon materials results from its possible applications. Fullerenes, single- and multi-wall carbon nanotubes, intercalated graphite, carbon composites, and nanodimond are the materials which play an essential role in electronics, informatics, nanotechnology, and medicine. Analogously to Silicon Valley it is possible that in the future there will be a Carbon Valley.

Superconductivity with relatively high $T_{\mathrm{c}} s$ was observed in carbon materials: at $T_{\mathrm{c}}=35 \mathrm{~K}$ in graphite-sulfur composites [1] and close to room temperature 
in higly oriented pyrolytic graphite (HOPG) [2], carbon nanotubes [3], and amorphous carbon [4]. In modified graphite, superconductivity occurs in a small sample fraction or is thermally unstable $[1,5]$. These observations need to be verified.

There is a distinct tendency in seeking materials superconducting at a high temperature. The possibility of shifting $T_{\mathrm{c}}$ upwards is known also in fullerenes $[6,7]$, where the dependence between $T_{\mathrm{c}}$ and the lattice constant is known as Fleming universality. It allows applying BCS dependence of $T_{\mathrm{c}}$ on the density of states at the Fermi level $N\left(E_{\mathrm{F}}\right)$ :

$$
k T_{\mathrm{c}}=\hbar \omega_{\mathrm{ph}} \exp \left[-1 /\left(\nu N\left(E_{\mathrm{F}}\right)\right)\right],
$$

where $k$ is the Boltzmann constant, $\hbar \omega_{\mathrm{ph}}$ - phonon energy, and $\nu$ - characterize electron-phonon coupling. From Eq. (1) it follows that there are two ways to increase $T_{\mathrm{c}}$ : either by enlarging the bandwidth (increase in lattice constant since $\left.N\left(E_{\mathrm{F}}\right) \sim a^{2}\right)$ or by increasing the number of carriers in the band (excess doping). For fullerene the graphite model [8] is known, which enables a universal approach to carbon materials. After strong intercalation, graphite intercalated compounds (GIC) may have also a much higher temperature $T_{\mathrm{c}}$ of the transition to the superconducting state. Potassium intercalated graphite with the excess of potassium gives the shift of $T_{\mathrm{c}}$ from $0.39 \mathrm{~K}$ to $0.55 \mathrm{~K}$ [9]. The pressure method applied to alkali metal intercalated graphite gives a strong increase in $T_{\mathrm{c}}$; for $\mathrm{C}_{x} \mathrm{Na}$ system with $x \sim 2, T_{\mathrm{c}}=5 \mathrm{~K}[10]$.

\section{2. $\mathbf{C}_{60}$ ions}

The perfect $\mathrm{C}_{60}$ molecule is diamagnetic. However, EPR spectra are observed even for very pure single crystals, polycrystalline samples as well as for fresh thin films of $\mathrm{C}_{60}$. These EPR signals reflect defective $\mathrm{C}_{60}$ structure and strongly depend on the sample preparation [11]. Defects lead to a weak paramagnetism characterized by a narrow EPR line $(\sim 2 \mathrm{Gs})$ at $g_{+} \sim 2.0025$ which is above the free electron value $\left(g_{0}=2.0023\right)$. The large ionization potential of fullerene molecule is expected to rule out the possibility of ionization of this molecule. Nevertheless $\mathrm{C}_{60}$ in fuming sulfuric acid gives at least one oxidized state with $g$ value above the free electron one [12]. Defected $\mathrm{C}_{60}^{+}$centers can be also generated by the exposure of $\mathrm{C}_{60}$ powders or thin films to air (oxygen) and/or light (visible or UV) [13-16].

When solid $\mathrm{C}_{60}$ is doped with alkali metals the doped atoms donate one electron, each to $t_{1 \mathrm{u}}$ band of $\mathrm{C}_{60}$. This way negatively charged fullerene paramagnetic centers can be generated. The first effect of this process is the decrease of $\mathrm{C}_{60}^{+} \mathrm{EPR}$ signal - the electron introduced into the system from a donor neutralizes the positively charged $\mathrm{C}_{60}$ [16]. At the same time another EPR signal evolves due to the generation of negative $\mathrm{C}_{60}^{n-}$ radicals [7]. The appearance of $\mathrm{C}_{60}^{1-}$ and $\mathrm{C}_{60}^{3-}$ fullerene centers corresponds to the formation of $\mathrm{A}_{1} \mathrm{C}_{60}$ and $\mathrm{A}_{3} \mathrm{C}_{60}$ phases, respectively. In the $\mathrm{A}_{1} \mathrm{C}_{60}$ structure octahedral voids of $\mathrm{C}_{60}$ structure are occupied by $\mathrm{A}^{1+}$ ions, 
whereas the $\mathrm{A}_{3} \mathrm{C}_{60}$ phase is characterized by $\mathrm{A}^{1+}$ occupancy of both octa- and tetrahedral sites. The radicals formed during the intercalation of the alkali donors are characterized by the following $g$-factor values: $g_{1-}=1.9998 \pm 0.0001\left(\mathrm{C}_{60}^{1-}\right)$ and $g_{3-}=2.0014 \pm 0.0001\left(\mathrm{C}_{60}^{3-}\right)$. These EPR lines overlap at room temperature (RT). To separate the $\mathrm{C}_{60}^{1-}$ and $\mathrm{C}_{60}^{3-}$ EPR signals the samples were cooled down below $50 \mathrm{~K}$ where it is possible to distinguish individual $\mathrm{C}_{60}^{1-}$ and $\mathrm{C}_{60}^{3-}$ lines [17]. The concurrence of the $g$-values of $\mathrm{C}_{60}^{1-}$ and $\mathrm{C}_{60}^{3-}$ formed by both the donors, potassium and rubidium, implies that the charge is localized at the low temperatures on a $\mathrm{C}_{60}$ molecule. The narrowing of the EPR lines on cooling confirms such localization in the $v \mathrm{~A}^{+} \mathrm{C}_{60}^{v-}(v-$ valency) complexes [7]. This procedure gives us an occasion to be very close to the superconducting transition with the well-defined system by EPR. Superconducting transition was studied by magnetically modulated microwave absorption (MMMA) method which uses an EPR spectrometer with the external field off, when the absorption of microwave energy by intra- and inter-grain Josephson junctions can be recorded $[18,19]$.

\section{Superconductivity of $\mathbf{A}_{x} \mathbf{C}_{60}$}

The process of the formation of the superconducting phase has been studied in detail from the very beginning by EPR and MMMA methods. The EPR detects the appearance and evolution of the EPR signals due to the paramagnetic centers formed during the process, leading to the formation of superconducting $\mathrm{A}_{3} \mathrm{C}_{60}$. Superconductivity was diagnosed by a MMMA method that became a well-documented test for superconductivity [18].

$$
\text { 3.1. } K_{x} C_{60}
$$

$\mathrm{K}$-doping of $\mathrm{C}_{60}$ can be realized by different procedures. A slow increase in the temperature of a $\mathrm{K}+\mathrm{C}_{60}$ mixture leads immediately to the $\mathrm{K}_{3} \mathrm{C}_{60}$ phase as reported in the Raman study [20]. It means that octahedral and tetrahedral sites of $\mathrm{C}_{60}$ structure are being filled simultaneously by potassium ions. The $\mathrm{K}_{1} \mathrm{C}_{60}$ phase could be observed at higher temperatures [20, 21]. Raman studies also showed that the front potassium ions propagate from the fore side to the back side of the $\mathrm{C}_{60}$ film.

Another method is based on prolonged heating of a $\left(\mathrm{K}+\mathrm{C}_{60}\right)$ mixture at $T \approx 450 \mathrm{~K}$ and then on slow cooling to ambient temperature. This procedure (for $x \leq 3$ ) leads to a decomposition of $\mathrm{K}_{1} \mathrm{C}_{60}$ to $\alpha-\mathrm{C}_{60}$ and $\mathrm{K}_{3} \mathrm{C}_{60}$. The process is reversible in accordance with the eutectoidal phase diagram of $\mathrm{K}_{x} \mathrm{C}_{60}$ [22-25].

The next procedure of $\mathrm{K}$ doping can lead to a polymer or dimer structure [26-28]. The heating of the mixture above $450 \mathrm{~K}$ gives a homogeneous $\mathrm{K}_{1} \mathrm{C}_{60}$ phase. A stable in air and insoluble in toluene dimer $\mathrm{KC}_{60}$ phase could be formed by quenching this phase to RT or helium temperature. Superconductivity is absent in the dimer $\mathrm{KC}_{60}$ phase $[27,28]$. 
An unstable superconducting phase with $T_{\mathrm{c}}^{(1)}=21 \mathrm{~K}$, i.e. the $2.5 \mathrm{~K}$ upward shift, in critical temperature compared to that of bulk $\mathrm{K}_{3} \mathrm{C}_{60}$ [7], is observed in $\mathrm{K}_{x} \mathrm{C}_{60}$ at low doping level where strong $\mathrm{C}_{60}^{1-}$ and $\mathrm{C}_{60}^{3-}$ EPR signals are present in the EPR spectrum. Each step of doping process was monitored by the EPR to follow evolution of spins. Superconductivity was monitored by MMMA right after the EPR spectrum had been recorded. The $T_{\mathrm{c}}$ upward shift is explained with the consideration of radial distribution of $\alpha-\mathrm{C}_{60}\left(x \leq 0.1\right.$ [29]), $\mathrm{K}_{1} \mathrm{C}_{60}$, and $\mathrm{K}_{3} \mathrm{C}_{60}$ phases in every $\mathrm{C}_{60}$ granule at the low doping level, Fig. 1 [30]. Fast K diffusion at temperatures above $450 \mathrm{~K}$ forms a $\mathrm{K}^{+}$front which propagates leaving behind local zones of $\alpha-\mathrm{C}_{60}, \mathrm{~K}_{1} \mathrm{C}_{60}$, and $\mathrm{K}_{3} \mathrm{C}_{60}$ phases. When the sample is transferred from the furnace to the EPR spectrometer and cool down, first to ambient temperature and then to temperatures below $50 \mathrm{~K}$, the formation of dimer $\mathrm{KC}_{60}$ structure of $\mathrm{K}_{1} \mathrm{C}_{60}$ is favored [26, 27, 31,32]. The strain at the boundary of $\mathrm{KC}_{60}$ and $\mathrm{K}_{3} \mathrm{C}_{60}$ (Fig. 1) leads to expansion of $\mathrm{K}_{3} \mathrm{C}_{60}$ unit adjoining the compressed dimer layer. According to Fleming universality and Eq. (1) the expanded $\mathrm{K}_{3} \mathrm{C}_{60}$ sublayer exhibits superconductivity with a critical temperature $T_{\mathrm{c}}^{(1)}=21 \mathrm{~K}$. Fleming universality tested by Zhou et al. [33] in pressure measurements gives a slop of $33 \mathrm{~K} / \AA$. This coefficient leads to a change in lattice parameter $\Delta a=0.075 \AA$ for the $T_{\mathrm{c}}$ shift observed in our experiment: $\Delta T_{\mathrm{c}}=2.5 \mathrm{~K}$. From X-ray measurements the dimer transformation results in a drop of volume $\Delta V / V \approx 1.8 \%$ [26] which gives $\Delta a=0.09 \AA$. The superconducting phase characterized by $T_{\mathrm{c}}^{(1)}=21 \mathrm{~K}$ is metastable - it vanishes when the doping process is brought to the end [7].

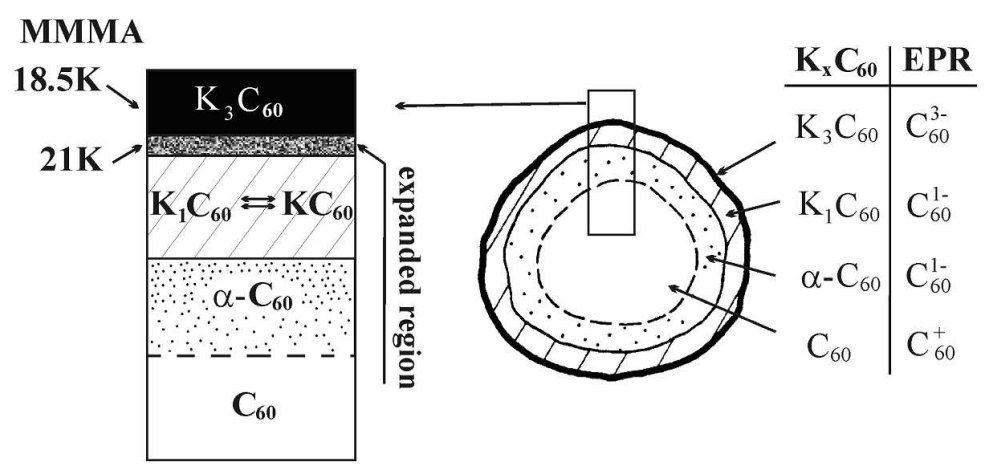

Fig. 1. Model of layered structure of $\mathrm{K}_{x} \mathrm{C}_{60}$ phases within a $\mathrm{C}_{60}$ granule and creation of superconducting phase with $T_{\mathrm{c}}^{(1)}=21 \mathrm{~K}$ by local expansion of $\mathrm{K}_{3} \mathrm{C}_{60}$ phase as a result of $\mathrm{K}_{1} \mathrm{C}_{60} \leftrightarrow \mathrm{KC}_{60}$ transformation.

Based on Fleming universality the next possible explanation of the locally expanded $\mathrm{K}_{3} \mathrm{C}_{60}$ phase is proposed [34]. The critical temperature $T_{\mathrm{c}}$ upward shift (from $18.5 \mathrm{~K}$ to $21 \mathrm{~K}$ ) is ascribed to the possible process of appearing $\mathrm{K}^{1-}$ ions. This process is called potassium transient back charge transfer [34]. According to this process valency changes as follows: $3 \mathrm{~K}^{1+}+\mathrm{C}_{60}^{3-} \leftrightarrow 2 \mathrm{~K}^{1+}+\mathrm{K}^{1-}+\mathrm{C}_{60}^{1-}$. The 
appearing of $\mathrm{K}^{1-}$ ions of a large radius $\left(r^{\mathrm{K} 1-}=2.31 \AA\right)$ compared to $r^{\mathrm{K} 1+}=$ $1.33 \AA$ could enlarge the unit cell necessary to shift superconducting temperature according to the dependence between $T_{\mathrm{c}}$ and the lattice constant. For such process $10 \%$ of excited phase is required at the reaction front.

Both models are constructed in agreement to the pressure coefficient for the superconducting critical temperature $\Delta T_{\mathrm{c}} / \Delta p=-7.8 \mathrm{~K} / \mathrm{GPa}$ for $\mathrm{K}_{3} \mathrm{C}_{60}$ [35].

$$
\text { 3.2. } R b_{x} C_{60}
$$

In the $\mathrm{C}_{60}$ fcc structure there are spacious octahedral and smaller tetrahedral sites with diameters of $r=2.06 \AA$ and $r=1.12 \AA$, respectively. These sites become occupied during the alkali metal intercalation process. Since alkali ion radii are $r^{\mathrm{K}+}=1.33 \AA$ and $r^{\mathrm{Rb}+}=1.47 \AA$, the rubidium intercalation process is much slower compared to potassium one. It enables us to determine the kinetics of the decrease of the $\mathrm{C}_{60}^{+}$signal versus time of the reaction for the $\mathrm{Rb}$ intercalated $\mathrm{C}_{60}[16]$. After the first $7 \mathrm{~h}$ of $\mathrm{Rb}$ doping, besides the $\mathrm{C}_{60}^{+}$line decreasing, the weak $\mathrm{C}_{60}^{1-}$ signal increases slightly whereas the $\mathrm{C}_{60}^{3-}$ intensity grows rapidly. Such a situation corresponds to the nucleation of the $\mathrm{Rb}_{3} \mathrm{C}_{60}$ phase before the $x=1$ composition of $\mathrm{Rb}_{x} \mathrm{C}_{60}$ is reached. Additionally, the decay of the $\mathrm{C}_{60}^{+}$ signal corresponds to the $\mathrm{Rb}$ diffusion into the $\mathrm{C}_{60}$ grains [16]. Therefore, after $60 \mathrm{~h}$, when the $\mathrm{C}_{60}^{+}$signal is neutralized, rubidium ions might have reached the core of the $\mathrm{C}_{60}$ grain. The MMMA signal shows a superconducting transition at $T_{\mathrm{c}}=30 \mathrm{~K}$. After $60 \mathrm{~h}$ of doping, when the $\mathrm{C}_{60}^{+}$signal is no longer present in the EPR spectrum, a new broader EPR component appears. This new line has a very characteristic of $\mathrm{C}_{60}^{3-}$ radical $g$-factor of 2.0014 and a half width of 6 Gs at $31 \mathrm{~K}$. On further doping, this new component grows in intensity whereas the weak $\mathrm{C}_{60}^{1-}$ signal slowly decreases and the narrow $\mathrm{C}_{60}^{3-}$ line decreases rapidly - the broad line grows in intensity at the expense of the narrow $\mathrm{C}_{60}^{3-}$ one [36]. This allows us to ascribe the broad component to the $\mathrm{Rb}_{3} \mathrm{C}_{60}$ phase formed from the nucleated phase (characterized by a narrow $\mathrm{C}_{60}^{3-}$ component). Another words local $\mathrm{Rb}_{3} \mathrm{C}_{60}$ islands join to create a global $\mathrm{Rb}_{3} \mathrm{C}_{60}$ stable phase. The change in the linewidth is related to the transition from localized states in the nucleated phase to the extended states in the $\mathrm{Rb}_{3} \mathrm{C}_{60}$ phase.

Around this special $60 \mathrm{~h}$ doping level (Fig. 2a), strong, noisy oscillations appear on the MMMA signal below $17 \mathrm{~K}$ (Fig. 2b). The appearance of MMMA oscillations coincides with a broad line formation, which we attributed to the clustering of nucleated $\mathrm{Rb}_{3} \mathrm{C}_{60}$ phase. Diffusion of alkali ions occurs not only at a high temperature but also at a low temperature [25]. Thus, an unstable population of octahedral or tetrahedral voids in the fullerene structure can lead to local percolation breakdown in the superconducting network [37, 38]. The oscillations disappear at a higher doping level when $\mathrm{Rb}_{3} \mathrm{C}_{60}$ nuclei start to form the stable $\mathrm{Rb}_{3} \mathrm{C}_{60}$ phase. Therefore, at this stage of doping, such oscillations can be generated by a randomly distributed network of $\mathrm{Rb}_{3} \mathrm{C}_{60}$ nuclei. This strongly 

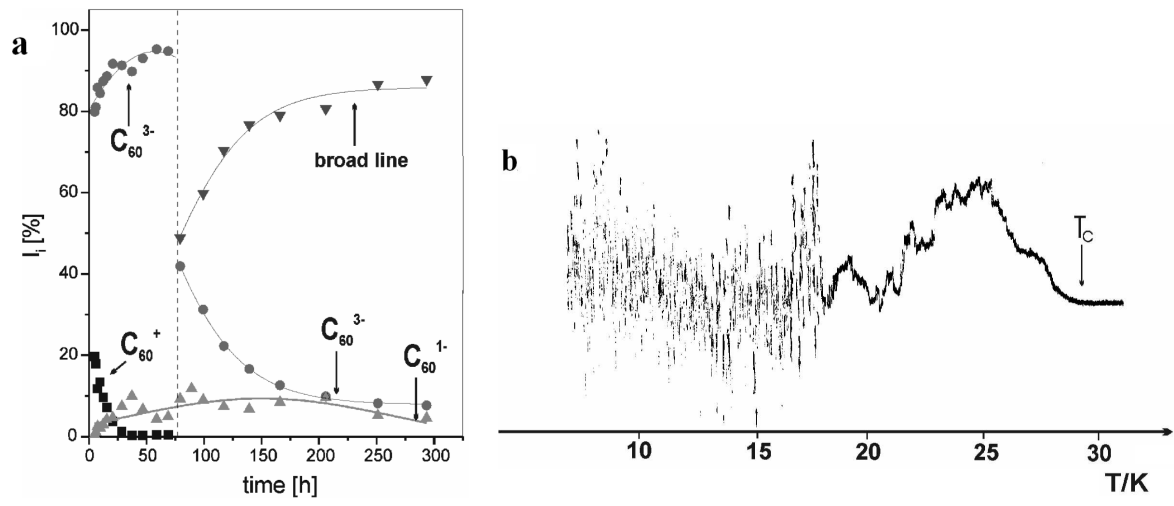

Fig. 2. (a) Integral intensity $I_{i}$ of each spectrum component versus time of Rb intercalation as the number of spins corresponding to each spectrum component relative to the total number of spins (\%) observed at this stage of doping. Dashed line shows the region in which MMMA (b) oscillations for an unstable $\mathrm{Rb}_{3} \mathrm{C}_{60}$ nuclei network at the $60 \mathrm{~h}$ doping level appeared.

confirms our model of Rb distribution, whose kinetics could be described by the Avrami equation [36].

\section{3. $H O P G+$ potassium}

The first stage intercalation of HOPG gives $\mathrm{C}_{8} \mathrm{~K}$ stoichiometry with superconducting transition observed at $T_{\mathrm{c}}=0.39 \mathrm{~K}$. If a small excess of potassium appears in the system, $T_{\mathrm{c}}$ is shifted upward to $0.55 \mathrm{~K}$ [9]. Dense potassium-graphite systems can be obtained in two ways: using the high pressure or by reaction between graphite and liquid potassium containing a small amount of oxygen. The formation of dense phases in K-graphite system results in a higher critical temperature of superconducting transition $T_{\mathrm{c}}$. For pressure induced $\mathrm{C}_{3} \mathrm{~K}$, the transition to superconducting state occurs at $T_{\mathrm{c}}=3 \mathrm{~K}[10]$.

We measured two kinds of potassium-graphite samples: $\mathrm{C}_{8} \mathrm{~K}_{\mathrm{ex}}$ (with a small excess of potassium) and $\mathrm{C}_{6} \mathrm{KO}_{y}$ with $y<0.2\left(\mathrm{C}_{4} \mathrm{KO}_{x}\right.$ potassium double layer + $\left.\mathrm{C}_{8} \mathrm{~K}, x<0.2\right)$. The EPR spectra of $\mathrm{C}_{8} \mathrm{~K}_{\text {ex }}$ and $\mathrm{C}_{6} \mathrm{KO}_{y}$ are complex. The analysis of these spectra, based on Feher, Lauginie or Koder method [39-41] allows one to decompose them into Dysonian and Lorentzian lines and to estimate their relative contributions. For $\mathrm{C}_{8} \mathrm{~K}_{\mathrm{ex}}$ Dysonian line at $g_{\perp}=2.0032$ with $g_{\perp}-g_{0}=9 \times 10^{-4}$ is typical of stoichiometric $\mathrm{C}_{8} \mathrm{~K}$ [39] ( $g$ error $\left.\pm 1 \times 10^{-4}\right)$. On lowering temperature from room temperature to $4 \mathrm{~K}$, the Dysonian component in $\mathrm{C}_{8} \mathrm{~K}_{\mathrm{ex}}$ spectrum coincides with temperature dependence of the EPR spectrum of $\mathrm{C}_{8} \mathrm{~K}$ sample (a stoichiometric one). The second component, the Lorentzian one at $g=2.0045$, is due to localized electrons. This component follows the Curie law on cooling.

On lowering temperature, very strong oscillations in the EPR spectrum have been observed for both GIC systems below $150 \mathrm{~K}$, Fig. 3a. These oscillations make 


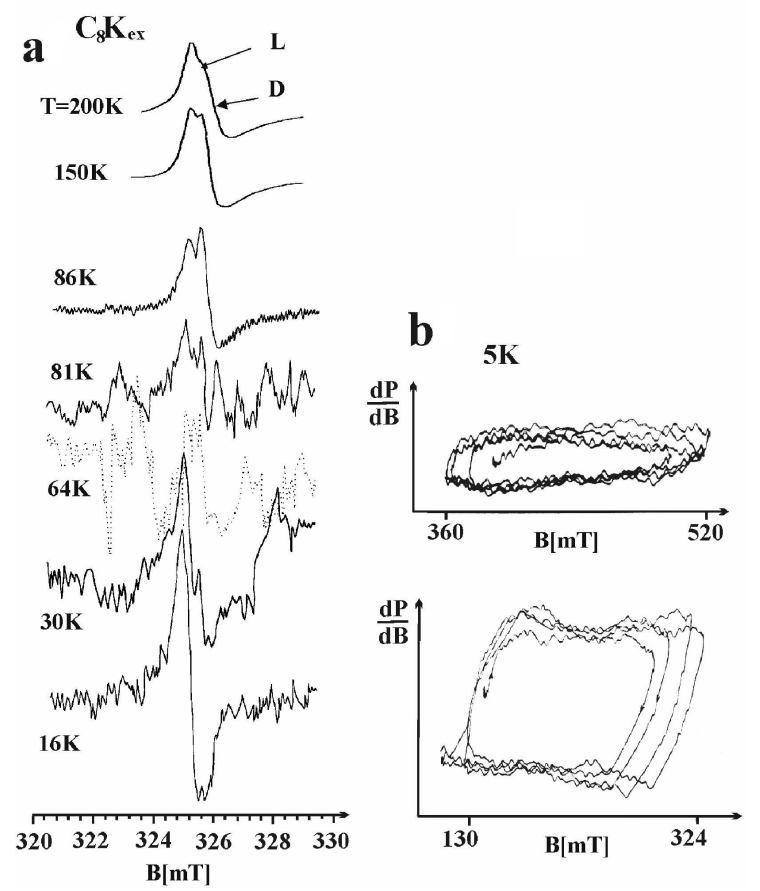

Fig. 3. (a) EPR of $\mathrm{C}_{8} \mathrm{~K}_{\text {ex }}$ with strong oscillations below $100 \mathrm{~K} . L$ and $D$ mark Lorenzian and Dysonian components, respectively. (b) Josephson hysteresis loops characteristic of the trapped fluxes registered close to $5 \mathrm{~K}$ at two different magnetic field regions.

difficult to analyze EPR if not unable [42]. Generally, the temperature at which the oscillations occur, their range, and the amplitude of oscillations seem to occur at random. Such behavior can be related to local instability of stoichiometry in the studied samples. Oscillations of $\mathrm{C}_{6} \mathrm{KO}_{y}$ system differ from those observed for $\mathrm{C}_{8} \mathrm{~K}_{\mathrm{ex}}$ system in one significant point: for the former sample it was able to detect the time dependent stabilization of two component structure [42].

We propose that the local concentration of $\mathrm{C}_{6} \mathrm{~K}$ or even more dense $\mathrm{K}$ graphite structures are possible in $\mathrm{C}_{8} \mathrm{~K}_{\mathrm{ex}}$ sample. The cooling of the sample generates the stiffening of the graphite planes, hence potassium ions are forced to be redistributed between the planes. Therefore the EPR oscillations reflect jumplike displacements of potassium between neighboring hexagons of graphite plane. The amplitude of the oscillations depends on the number of electrons transferred from conduction band (Dysonian line characterized by two relaxation processes) to localized state (relatively narrow Lorentzian line, characterized by one relaxation process). Such changes should modulate the conducting band - as the result the conducting electrons give a broad EPR spectrum with fluctuating $g$-values. For example, in semiconducting systems the broad spectrum of $g$-values can be observed due to a different effective mass of carriers. 
The $\mathrm{C}_{6} \mathrm{KO}_{y}$ sample was a mixture of $\mathrm{C}_{8} \mathrm{~K}$ phase and $\mathrm{C}_{4} \mathrm{KO}_{x}(x<0.2)-$ potassium double layer phase [44]. The mixed two phases $\mathrm{C}_{4} \mathrm{KO}_{x}$ and $\mathrm{C}_{8} \mathrm{~K}$ can also easily redistribute potassium ions between stiffened graphitic planes on cooling. For both samples the phenomenon occurs accidentally in terms of temperature range because it is strongly related to thermal history of the sample: the rate of cooling of the sample, the temperature and time of storage of the sample between succeeding experiments.

The presence of superconducting state in $\mathrm{C}_{8} \mathrm{~K}_{\mathrm{ex}}$ was monitored by Josephson hysteresis loops characteristic of the trapped fluxes and registered close to $5 \mathrm{~K}$. Figure $3 \mathrm{~b}$ shows that less work must be done to depin vortices at a higher magnetic field where the system is closer to the superconducting transition of lowered $T_{\mathrm{c}}$. The registered $T_{\mathrm{c}}$ is at least 10 times higher compared to the $T_{\mathrm{c}}$ of stoichiometric $\mathrm{C}_{8} \mathrm{~K}$. It suggests the presence of a low content of superconducting phase of more dense $\mathrm{K}_{x} \mathrm{C}$ with $x<6$ [10]. The EPR behavior strongly confirms this interpretation. But the redistribution of potassium between the stiffened graphite planes destroys this local unstable superconducting subphases. After the first cooling run the superconducting behavior is no longer observed in the described system.

\section{Conclusions}

The evolution of structural changes observed by EPR in three different carbon materials strongly support the interpretation of experimental results for unstable superconducting behavior for these systems.

For $\mathrm{K}_{x} \mathrm{C}_{60}$ two superconducting phases were observed. The stable superconducting phase was registered at $18.5 \mathrm{~K}$ for a well-defined $\mathrm{K}_{3} \mathrm{C}_{60}$ structure. The unstable superconducting phase with $T_{\mathrm{c}}=21 \mathrm{~K}$ was observed at a low doping level of this system where the $\mathrm{K}_{3} \mathrm{C}_{60}$ phase can appear as a local phase of expanded unit cell. Two models are proposed for the observed behavior.

The nucleation of $\mathrm{Rb}_{3} \mathrm{C}_{60}$ and the final phase formation are confirmed by MMMA oscillations observed at the $60 \mathrm{~h}$ doping level, where randomly distributed weak links between $\mathrm{Rb}_{3} \mathrm{C}_{60}$ nuclei undergo local percolation breakdown in the superconducting network.

The redistribution of potassium between the stiffened graphite planes can create a dense local, unstable GIC structure. It enables one to observe a superconducting transformation for such system even at $T_{\mathrm{c}}=5 \mathrm{~K}$.

\section{Acknowledgments}

The author wishes to thank prof. Jan Stankowski and dr. Lidia Piekara-Sady for stimulating discussions. 


\section{References}

[1] R.R. da Silva, J.H.S. Torres, Y. Kopelevich, Phys. Rev. Lett. 87, 147001 (2001).

[2] Y. Kopelevich, P. Esquinazi, J.H.S. Torres, S. Moehlecke, J. Low Temp. Phys. 119, 691 (2000).

[3] G. Zhao, cond-mat/0307770.

[4] K. Antonowicz, Nature 247, 358 (1974).

[5] I.T. Belash, A.D. Bronnikov, O.V. Zharikov, A.V. Palnichenko, Solid State Commun. 64, 1445 (1987).

[6] R.M. Fleming, A.P. Ramirez, M.J. Rosseinsky, D.W. Murphy, R.C. Haddon, S.M. Zahurak, A.V. Makhija, Nature 352, 787 (1991).

[7] W. Kempiński, J. Stankowski, Solid State Commun. 97, 1079 (1996).

[8] J. Stankowski, L. Piekara-Sady, W. Kempiński, O. Huminiecki, P.B. Sczaniecki, Full. Sci. Technol. 5, 1203 (1997).

[9] N.B. Hannay, T.H. Geballe, B.T. Matthias, K. Andres, P. Schmidt, D. MacNair, Phys. Rev. Lett. 14, 225 (1965).

[10] I.T. Belash, O.V. Zharikov, A.V. Palnichenko, Synth. Met. 34, 445 (1989).

[11] W. Kempiński, J. Stankowski, Z. Trybuła, Sz. Łoś, Appl. Magn. Res. 8, 127 (1995).

[12] F. Rozpłoch, S. Jagielski, L. Nowak, J. Patyk, P. Szroeder, Mol. Phys. Rep. 18/19, 131 (1997).

[13] A.I. Shames, E.A. Katz, S.D. Goren, D. Faiman, S. Shtutina, Mater. Sci. Eng. $B$ 45, 134 (1997).

[14] E.A. Katz, A.I. Shames, D. Faiman, S. Shtutina, Y. Cohen, S.D. Goren, W. Kempiński, L. Piekara-Sady, Physica B 273/274, 934 (1999).

[15] M.D. Pace, T.C. Christidis, J.J. Yin, J. Phys. Chem. 96, 6855 (1992).

[16] W. Kempiński, L. Piekara-Sady, E.A. Katz, A.I. Shames, S. Shtutina, Solid State Commun. 114, 173 (2000).

[17] W. Kempiński, L. Piekara-Sady, J. Stankowski, in: Molecular Nanustructure, Eds. H. Kuzmany, J. Fink, M. Mehring, S. Roth, World Scientific, Hong Kong 1998, p. 249.

[18] J. Stankowski, B. Czyżak, Rev. Sci. Instrum. 64, 2930 (1993).

[19] J. Stankowski, B. Czyżak, J. Martinek, Phys. Rev. B 42, 13 (1990).

[20] M. Matus, H. Kuzmany, T. Pichler, M. Haluska, H. Winter, Synth. Met. 55, 3110 (1993).

[21] T. Pichler, R. Winkler, H. Kuzmany, Phys. Rev. B 49, 15879 (1994).

[22] W. Kempiński, J. Stankowski, Acta Phys. Pol. A 88, 549 (1995).

[23] D.M. Poirier, J.H. Weaver, Phys. Rev. B 47, 10959 (1993).

[24] D.M. Poirier, D.W. Owens, J.H. Weaver, Phys. Rev. B 51, 1830 (1995).

[25] W. Kempiński, Solid State Commun. 111, 39 (1999).

[26] Q. Zhu, D.E. Cox J.E. Fischer, Phys. Rev. B 51, 3966 (1995). 
[27] G. Oszlanyi, G. Bortel, G. Faigel, M. Tegze, L. Granasy, S. Pekker, P.W. Stephens, G. Bendele, R. Dinnebier, G. Mihaly, A. Janossy, O. Chauvet, L. Forro, Phys. Rev. $B$ 51, 12228 (1995).

[28] F. Bommeli. L. Degiogi, P. Wachter, O. Legeza, A. Janossy, G. Oszlanyi, O. Chauvet, L. Forro, Phys. Rev. B 51, 14794 (1995).

[29] D.M. Poirier, T.R. Ohno, G.H. Kroll, P.J. Benning, F. Stepniak, J.H. Weaver, L.P.F. Chibante, R.E. Smalley, Phys. Rev. B 47, 9870 (1993).

[30] W. Kempiński, P. Scharff, J. Stankowski, L. Piekara-Sady, Z. Trybuła, Physica C 274, 232 (1997).

[31] T. Kalber, G. Zimmer, M. Mehring, Phys. Rev. B 51, 16471 (1995).

[32] P. Petit, J. Robert, J.E. Fisher, Phys. Rev. B 51, 11924 (1995).

[33] O. Zhou, G.B.M. Voughan, Q. Zhu, J.E. Fisher, P.A. Heiney, N. Coustel, J.P. McCauley, A.B. Smith III, Science 255, 833 (1992).

[34] J. Stankowski, T. Luty, W. Kempiński, L. Piekara-Sady, Solid State Sci. 3, 531 (2001).

[35] G. Sparn, J.D. Thomson, S.-M. Huang, R.B. Kaner, F. Diderich, R.L. Whetten, G. Grüner, K. Holczer, Science 252, 1829 (1991).

[36] L. Piekara-Sady, W. Kempiński, B. Andrzejewski, L. Duclaux, Supercond. Sci. Technol. 17, 1 (2004).

[37] P.J. Leath, W. Tang, Phys. Rev. B 39, 6485 (1989).

[38] I.M. Gordon, M. Goldman, B. Whitehead, Phys. Rev. Lett. 59, 2311 (1987).

[39] P. Lauginie, H. Estrade, J. Conard, D. Guerard, P. Lagrange, M. El Makrini, Physica B 99, 514 (1980).

[40] G. Feher, A.F. Kip, Phys. Rev. 98, 337 (1955).

[41] H. Kodera, J. Phys. Soc. Jpn. 28, 89 (1970).

[42] W. Kempiński, L. Duclaux, J. Stankowski, F. Beguin, Polym. Bull. 47, 39 (2001).

[43] M.S. Dresselhaus, G. Dresselhaus, Adv. Phys. 30, 139 (1981).

[44] C. Herold, M. El Gadi, J.F. Mareche, P. Lagrange, Mol. Cryst. Liq. Cryst. 224, 41 (1994). 